\title{
MOVIMIENTO FEMINISTA E IGUALDAD DE DERECHOS. UNA LUCHA INACABADA.
}

\author{
FEMINIST MOVEMENT AND EQUAL RIGHTS. AN \\ UNACCOUNTABLE FIGHT \\ Núria Belloso Martín ${ }^{1}$ \\ Clóvis Gorczevski
}

\begin{abstract}
Recebido em: 03/05/2018 Aceito em: 02/06/2018

nubelo@ubu.es clovisg@unisc.br
\end{abstract}

La muerte del patriarcado se hace visible cuando una mujer toma conciencia del proceso que vive. Esa conciencia tiene como motor y precedente 'el amor a la libertad' de tantas mujeres que han vivido antes y que ahora viven. ${ }^{3}$

\section{CONSIDERACIONES INICIALES}

Una de las aportaciones de la modernidad política es la de haber desarrollado la idea de los derechos humanos. En el contexto de las revoluciones americana y francesa, acaecidas en a fines del siglo XVIII, se proclaman las declaraciones de derechos que abrieron camino al reconocimiento de derechos y libertades en las que, a través de los siglos posteriores, se ha venido trabajando, a nivel nacional, regional e internacional, hasta construir todo un sistema de protección de los derechos humanos.

Sin embargo, volviendo de nuevo a los albores de esos derechos, hay que advertir que la modernidad política no reconoció los derechos de participación política de las mujeres, concretamente, su derecho al sufragio. Posteriormente, en la época del desarrollo industrial del siglo $\mathrm{XIX}$, se les excluyó del trabajo asalariado o, como mucho, quedaron relegadas a desempeñar funciones de segunda categoría. A estos dos tipos de discriminación -política y laboral- hay que añadir la exclusión de las mujeres de la participación en la vida cultural así como la discriminación educativa. Resulta paradójico que, grandes filósofos de la política y del Derecho, adalides de la defensa de las libertades (Hobbes, Locke, Rousseau, Kant, Hegel), ${ }^{4}$ no consideraran a la mujer como

\footnotetext{
${ }^{1}$ Universidad de Burgos - Burgos - Espanha

${ }^{2}$ Universidade de Santa Cruz do Sul - UNISC - Santa Cruz do Sul - Rio Grande do Sul - Brasil

3 BIOSCA. Elena Grau. Feminismo. In: MELLÓN, Joan, Antón. Ideologías y movimientos políticos contemporáneos. 2. ed. Madrid: Tecnos, 2008. p. 406.

${ }^{4}$ Los teóricos del contrato social (Hobbes, Locke, Rousseau, Kant) preparan la llegada de las democracias modernas basadas en la libertad para suscribir contratos económicos y políticos. Pero la consideración de primacía de los hombres con respecto a las mujeres incide en que se delimiten dos ámbitos: el público, de los ciudadanos y trabajadores, y el doméstico, de subordinación de las mujeres. Las mujeres serán concebidas
} 
sujeto de derechos -como tampoco se había hecho en su momento con los esclavos y los niños-. Tampoco la teoría de la justicia de Rawls ni la teoría crítica de la dominación (construida por filósofos de la Escuela de Frankfurt como Adorno, Marcuse y Habermas) se han ocupado de la perspectiva de género. ${ }^{5}$

Esta exclusión de las mujeres de la titularidad de derechos ha provocado una discriminación histórica con graves consecuencias, desembocando en graves desigualdades sociales, políticas, económicas y jurídicas (la mujer carece de iguales oportunidades que los hombres en el acceso al mercado de trabajo y en los salarios, menor índice de alfabetización, el derecho al sufragio femenino es una conquista reciente y la participación política femenina en puestos de alta responsabilidad tiene un porcentaje muy bajo). ${ }^{6}$ Se trata de una cuestión compleja porque incide en múltiples vertientes (derechos humanos, igualdad, discriminación, igualdad, subordinación y diferencia, feminismo, patriarcalismo, género, sexo) lo que provoca que se incentiven posiciones extremas que distorsionan un planteamiento acorde con la justicia y con los derechos humanos. Se llega a una bipolarización de la realidad humana en un modo de ser específicamente masculino y otro femenino, dando lugar a un contexto en el que generalmente domina el rol masculino. ${ }^{7} \mathrm{Y}$ esta dominación se ha proyectado también en el ámbito jurídico, dando lugar a normas que contenían discriminaciones con respecto a

como seres más naturales (por tanto, más vinculadas al estado de naturaleza) y menos racionales que los hombres, incapaces de controlar sus emociones para lograr la imparcialidad propia del ámbito público. Vid., entre otros, ROUSSEAU, J.J., “L'Emile ou l'education” en Oeuvres complètes de Jean Jacques Rousseau. Vol. IV. Paris: Gallimard, 1969, p.700-736; KANT., I., “Respuesta a la pregunta: ¿Qué es la llustración?” en AA.VV., ¿Qué es la llustración?, trad. de A. Maestre y J. Romagosa, Madrid: Tecnos, 1988, pp.9-10; HEGEL, J.G.F., Filosofía de la Historia universal. Trad. de J. Gaos, Madrid: Revista de Occidente, 1928.

${ }^{5} \mathrm{Ha}$ habido algunas reivindicaciones al respecto, escasas pero relevantes, tales como la Declaración de los derechos de la mujer y de la ciudadanía, en 1791, de Olympe de Gouges; la Vindicación de los derechos de la mujer, en 1792, de Mary Woolstonecraft; y la petición de voto para las mujeres, de J. Stuart Mill y de H. Taylor. ${ }^{6} \mathrm{Ha}$ habido aportaciones teóricas relevantes a la filosofía política del feminismo procedentes del ámbito británico y norteamericano tales como: GILLIGAN, C., In a Different Voice. Psychological Theory and Women's Development. Cambrigde: Harvard University Press, 1982; PATEMAN, C. The Sexual Contract, Cambridge:Oxfor,d,, 1988; PHILLIPS, A., ¿Las feministas deben abandonar la democracia liberal?, en: "Perspectivas feministas en Teoría política", YOUNG, I.M., Justice and the Politics of Difference. Trad. de S. Álvarez. La justicia y la política de la diferencia. Madrid: Cátedra-Universitát de Valencia-Instituto de la mujer, 2000.

En el ámbito español, hay que destacar las aportaciones del feminismo ilustrado de Adolfo Posada, desde la corriente del krausismo, reflejadas en la obra de Concepción Arenal o de Emilia Pardo Bazán. En cuanto al ámbito jurídico actual, reseñamos: FERNÁNDEZ, E., "Los derechos de las mujeres" en J. Ballesteros (Editor) Derechos humanos. Concepto, fundamento, sujetos, Madrid: Tecnos, 1992, pp.144-151; OLLERO, A., Discriminación por razón de sexo. Valores, principios y normas en la jurisprudencia constitucional española. Madrid: CEC, 1999; RUIZ MIGUEL, A., "Paridad electoral y cuotas femeninas" en Claves de Razón Práctica, 94, 1999, p.52 ss; PECES-BARBA, G., Curso de Derechos fundamentales. Teoría General. Madrid:BOE-Universidad Carlos III, 1995, pp.180-181; PECES-BARBA, G., "De la igualdad normativa a la igualdad de hecho. Las cuotas femeninas en las elecciones" en J.A. López García y J.A. del Real (Editores) Los derechos: entre la ética, el poder y el Derecho, Madrid: Dykinson, 2000, pp.169-180; REY MARTíNEZ, F., El derecho fundamental a no ser discriminado por razón de sexo. Madrid: McGraw-Hill, 1995; DURÁN Y LALAGUNA, P., "La definición del género" en Los límites del Derecho, Granada: Comares, 1996; BELTRÁN PEREIRA, E., "Público y Privado (Sobre feminsitas y liberales: argumentos en un debate acerca de los límites de lo político)" en DOXA, no15-16, 1994, pp.389-405. Disponible en: <www.cervantesvirtual.com/.../pblico-y-privado--sobre-feministas-y-liberalesargument...>.

7 BOURDIEU, P., La domination masculine. Trad. de J. Jordá. La dominación masculina. 2a ed., Barcelona: Anagrama, 2000. 
las mujeres. Warat ya advertía que el Derecho sigue un modelo masculino y que la justicia es un valor adherido al ideal normativo de la masculinidad. El hombre se ve a sí mismo como portador natural de un sentido de justicia (sentido de justicia que parece ser que falta a las mujeres). ${ }^{8}$

Esta situación de subordinación de la mujer provocó movimientos de reivindicación de derechos de las mujeres (principalmente tanto mediante el sufragismo como a través de otros movimientos de liberación de la mujer). Actualmente, que advertir que, si bien se han logrado una igualdad formal, el reto estriba en lograr pasar de una igualdad de iure a una igualdad de facto, es decir, a una igualdad material real. Para ello, se han adoptado diversas medidas tales como actuaciones de discriminación positiva, ${ }^{9}$ legislación penal y procesal sobre prevención y lucha contra la violencia doméstica ${ }^{10} \mathrm{y}$ contra la explotación por motivos sexuales.

En el presente trabajo vamos a limitarnos a analizar sólo alguna de las cuestiones a las que hemos hecho referencia, subrayando aquellos hitos que, poco a poco, han ido tejiendo el movimiento feminista por la igualdad, una lucha aún inacabada.

Tomando como punto de partida, lo que ponen de manifiesto los restos paleontológicos encontrados, la vocación natural por la vida social y la distribución del trabajo, así como los rasgos propios de la morfología masculina y femenina, la desigualdad entre hombre y mujer, marca los orígenes del patriarcado que, durante tantos siglos ha estado vigente.

Los estudios arqueológicos y antropológicos han puesto de manifiesto que la primera organización social humana ha sido la horda, en la cual, el eslabón entre sus integrantes era la filiación materna. La mujer conducía el grupo y todos seguían a la madre, que los alimentaba y protegía. Será más tarde cuando, con el reconocimiento de vínculos de parentesco a través de la sangre, el estadio social evolucione de la horda a la familia, cuya máxima autoridad está confiada generalmente a un jefe varón.

De los hallazgos paleontológicos encontrados, se puede afirmar que los más primitivos homínidos ya componían pequeños grupos sociales, y que su alimentación se basaba en frutos, semillas, raíces, insectos, pequeños vertebrados y, ocasionalmente, uniendo fuerzas lograban abatir predadores mayores; compartían el mismo espacio en grutas, cuevas o en escondrijos naturales.

El grupo familiar de cazadores-colectores estaba compuesto de cinco a ocho individuos de ambos sexos y de todas las edades. El hecho de que iniciaran actividades agrícolas y de domesticación de los animales los hizo sedentarios. Sin embargo, la vida más estable, con la consecuente creación de la aldea fue obra de la mujer, precedida de una revolución sexual. Este cambio, según Mumford,

deu predomínio não ao macho, caçador, ágil, de pés velozes, pronto para matar, impiedoso por necessidade vocacional, porém à fêmea, mais

\footnotetext{
${ }^{8}$ Cfr. WARAT, L.A., "A questâo do gênero", en Por quem cantam as sereias. Informe sobre Ecocidadania, Gênero e Direito, Porto Alegre: Síntese, 2000, p.137.

${ }^{9}$ La discriminación positiva es una política social dirigida a mejorar la calidad de vida de grupos desfavorecidos, proporcionándoles la oportunidad efectiva de equiparar su situación de mayor desventaja social.

${ }^{10}$ Vid. BELLOSO MARTíN, N., "Algunas propuestas para la prevención y la lucha contra la violencia de género: reflexiones sobre la oportunidad de la tipificación del feminicidio" en Clovis Gorzevski (Organizador), Direitos Humanos e participacâo politica. Vol. VI, Porto Alegre: Imprensalivre, 2015, pp. 65-102.
} 
passiva, presa aos filhos, os rebentos, inclusive, ocasionalmente, a pequenos mamíferos lactentes, se a mãe destes morria, plantando sementes e vigiando as mudas..... ${ }^{11}$

Con el desarrollo de esta incipiente sociedad, se ha alterado asimismo la función del cazador, que debido al buen manejo de las armas pasa a proteger la aldea, no sólo de las fieras, sino también de potenciales invasores. Así, por la protección que propicia, a través de la fuerza y de las armas, el cazador comienza también a ejercer poder sobre los demás, volviéndose más tarde jefe político, abriendo camino para el poder, haciéndose después el señor de la guerra, de la ley y de la tierra, así como propietario de personas (esclavos) y de las mujeres.

Para Wilson, las diferencias físicas (los hombres son, en promedio, del $20 \%$ al $30 \%$ más pesados que las mujeres; son más fuertes y rápidos; la proporción entre sus miembros, la torsión del esqueleto y la densidad de los músculos están particularmente adaptadas a las especialidades arcaicas de los cazadores-colectores ancestrales) y de temperamento (las mujeres son más tolerantes, dóciles, se imponen menos y son menos agresivas físicamente) ampliadas por la cultura, dieron origen a la dominación masculina. ${ }^{12}$

\section{LA LUCHA POR EL RECONOCIMIENTO DE LA IGUALDAD}

La lucha por el reconocimiento de la igualdad de derechos entre los sexos, al menos en el campo teórico, es tan antigua como la discriminación o la sumisión de las mujeres. En este sentido, Miguel afirma,

Que el feminismo ha existido siempre puede afirmarse en diferentes sentidos. En el sentido más amplio del término, siempre que las mujeres, individual o colectivamente, se han quejado de su injusto y amargo destino bajo el patriarcado y han reivindicado una situación diferente, una vida mejor. ${ }^{13}$

Como ejemplos prácticos podemos recordar a Safo, poetisa griega, nacida en Lesbos, que en el año 125 a.C. creó un centro destinado a la formación intelectual de las mujeres. En la Edad Media tenemos el ejemplo de Dña. Urraca, Reina de Castilla y León, que durante 13 años estuvo al frente de su ejército en importantes combates para defender el trono de su hijo, antes de morir en 1126. En las Cruzadas, los cronistas árabes describen el brío y el coraje con que luchaban las mujeres. En el siglo XII, el gran filósofo musulmán, Abu al-Walidibn Rushd, conocido en occidente como Averroes, atribuyó la miseria de las ciudades al impedimento de la participación femenina. En el siglo XIV surge Christine de Pisan, considerada la primera activista del movimiento femenino. Al enviudar, con 25

\footnotetext{
${ }^{11}$ MUMFORD, Lewis. A cidade na história: suas origens, transformações e perspectivas. 4a ed. São Paulo: Martins Fontes. 1998. p. 18.

12 WILSON. Edward O. Da natureza humana. Traducción de Geraldo Florsheim y Eduardo D’Ambrosio. São Paulo: Editora de la Universidade de São Paulo. 1981. p. 120 y ss.

13 MIGUEL, Ana de. "Feminismos". In: AMORÓs, Celia (org) 10 Palabras clave sobre mujer. 4a ed. Estella:evd.1995. p. 217.
} 
años y seis hijos, se dedicó a los estudios y a la literatura. Sus ideas revolucionaron los siglos XIV y XV y en sus tres obras (El Romance de la Rosa, Ciudad de las Mujeres y El Libro de las Tres Virtudes) defendió la igualdad entre hombres y mujeres fundada en la propia naturaleza. Polemizó con intelectuales famosos de su época, defendiendo la igualdad entre los sexos y la necesidad de dar a las niñas la misma educación que era dada a los niños. La reina española, Isabel la católica, que apoyó a Cristóbal Colón en su viaje al Nuevo Mundo e hizo posible el descubrimiento. En los inicios del siglo XVI, destacamos a Guillaume Postel y François Villon. El primero examinó la situación de la mujer con relación al hombre y consideró que la mujer ocupaba un puesto subalterno porque el hombre abusó del poder que le ha dado Dios. El segundo recurrió a argumentos teológicos para probar la igualdad. Concluyó que el estado de inferioridad de la mujer con relación al hombre venía provocado por la falta de educación. En el siglo XVII hay que poner de relieve la aportación de Marie de Gournay que, con su obra "Tratado de Igualdad de los Hombres y Mujeres", en el que ataca abiertamente el principio de la superioridad masculina. Siguiendo la línea de Villon, defendía que la diferencia estaba en la educación. En América, también en el siglo XVII emerge Ann Hutchinson, la primera feminista estadounidense que, contrariando los dogmas calvinistas de la superioridad masculina, sostiene que hombres y mujeres fueron creados iguales por Dios. ${ }^{14}$

Por todo este iter histórico, no parece correcto, al menos en términos cronológicos, incluir el movimiento feminista, o movimiento de defensa de los derechos de las mujeres, en el rol de los nuevos movimientos sociales.

Efectivamente, un movimiento más organizado, amplio y omnicomprensivo, como acción orquestada de carácter colectivo que pretende cambiar la situación de la mujer en la sociedad, eliminando las discriminaciones a las que está sujeta, sólo conseguirá surgir en el ámbito de cambios más profundos que marcaron la historia de Europa Occidental a partir del siglo XVIII. ${ }^{15}$ Petit es categórica al afirmar que

El feminismo, como teoría articulada en torno a la crítica de la situación de inferioridad de la mujer es un producto ilustrado, y los primeros movimientos de mujeres en la lucha, dispuestas a cambiar su situación, se organizan bajo las banderas de la revolución Francesa. Feminismo e llustración, son, pues, fenómenos implicados en su teoría y en su historia. ${ }^{16}$

Ese feminismo era asimismo denominado iluminista, puesto que sus pensadoras se sitúan dentro del paradigma filosófico del iluminismo europeo, cuya filosofía era de un Estado como resultado del contrato social para protección de los derechos individuales de todos. La primera reivindicación feminista fue la inclusión de las mujeres en este "todos", es decir, el reconocimiento de

\footnotetext{
${ }^{14}$ ALAMBERT, Zuleika. Feminismo. O ponto de vista marxista. São Paulo: Nobel, 1986. p. 4-6; Las feministas de la Edad Media. In: XL Semanal nº 1218 (27.02.2011), pp. 52-57.

15 TOSCANO, Moema; GOLDENBERG, Mirian. A revolução das mulheres: um balanço do feminismo no Brasil. Rio de Janeiro: Revan, 1992. p. 17.

${ }^{16}$ PETIT, Cristina Molina. "Ilustración”. In: AMORÓS, Celia (org) 10 Palabras clave sobre mujer. 4a ed. Estella: evd. 1995. p. 189.
} 
su ciudadanía. ${ }^{17}$ Entonces, los ideales de la Revolución Francesa les dieron una apariencia de modernidad, porque propiciaron el descubrimiento de que la lucha de clases no escondía la lucha de los sexos y la toma de conciencia de que la opresión de las mujeres se producía en cualquier clase social.

Aun así, en el auge de la revolución política que va a moldear la modernidad, la lucha de las mujeres - sumada a la de los conflictos políticos globales y por derechos de igualdad de sexo continúa ignominiosa. Hay registros de, al menos, 374 ejecuciones de mujeres en el periodo del terror. En este contexto francés, destaca Olympe de Gouges, dramaturga, activista política, feminista, abolicionista y defensora radical de la igualdad de sexos. Abrazó con pasión la causa de la Revolución, sin embargo, pronto se decepcionó al constatar que el 'todos' no incluía a 'todas'. Sus trabajos afrontaban directamente los rumbos que había tomado la Revolución. ${ }^{18}$ Acusada de antirevolucionaria y mujer desnaturalizada, fue condenada a la muerte, justificándolo Robespierre, por "haber querido ser hombre de Estado y olvidarse las virtudes propias de su sexo". Al ser llevada a la guillotina, expresó la famosa frase: "si la mujer tiene el derecho de subir al patíbulo, debe igualmente tener el derecho de subir a la tribuna".

El feminismo - como aquella tradición política de la Modernidad, igualitaria y democrática, que mantiene que ningún individuo de la especie humana debe ser excluido de cualquier bien y de ningún derecho a causa de su sexo ${ }^{19}$ - nació con el iluminismo, pero se trata de un hijo no deseado. Recuerda Valcárcel que la democracia de Rousseau era excluyente y cimentaba la igualdad entre los hombres en la preponderancia sobre las mujeres. Para Rousseau, el estado ideal es una república en la cual cada varón es jefe de familia y ciudadano. "Las mujeres son un segundo sexo y su educación debe garantizar que cumplan su cometido: agradar, ayudar, crear a los hijos. Para ellas no han sido hechos los libros, tampoco las tribunas. Su libertad es odiosa y rebaja la calidad moral del conjunto social". En una línea semejante se desarrolla el pensamiento lockeano. ${ }^{20}$

Incidiendo en la lucha de reconocimiento como sujeto político, las revolucionarias comienzan el movimiento sufragista - bandera femenina entre 1850-1930. Las mujeres, especialmente las trabajadoras, ya tenían larga tradición de protestas - algunas violentas - en el campo y en las ciudades, en las revueltas y en las luchas populares. Participaron activamente en la toma de la Bastilla en julio de 1789, así como en todos los acontecimientos políticos que se desarrollaron durante la Revolución Francesa. En las revoluciones ciudadanas de 1848 que explotaron en París, Viena, Milán, Roma, Berlín y en otras importantes ciudades europeas, las mujeres siguieron

17 BIOSCA. Elena Grau. Feminismo. In: MELLóN, Joan, Antón. Ideologías y Movimientos Políticos Contemporáneos. 2. ed. Madrid: Tecnos, 2008. p. 406.

${ }^{18}$ Entre sus numerosos trabajos, citamos: Declaración de los Derechos de la Mujer y de la Ciudadana, en el que expresaba que "La mujer nace libre y tiene los mismos derechos del hombre", y L'Esclavage des Nègres, que combate duramente la esclavitud, el Contrato Social, inspirada en la obra de Rousseau, propone matrimonios con condiciones de igualdad entre las dos personas, la pieza teatral Les trois urnes, ou le salut de la Patrie, par um voyageuraérien predicaba la realización de un plebiscito para elegir una de las tres formas de gobierno: República Indivisible, Gobierno Federalista o Monarquía Constitucional. Este último trabajo le supuso una condena de cárcel.

${ }^{19}$ VALCÁRCEL, Amelia. Feminismo en el mundo global. 4a ed. Madrid: Cátedra/Universitat de València. 2012. p. 55.

${ }^{20}$ Idem. p. 62 
participando activamente, inclusive "vistiéndose con improvisados uniformes y portando armas". ${ }^{21}$ Otto relata la lucha de las mujeres en defensa de estas breves repúblicas describiendo una batalla de la que fue testigo, acaecida en 1849:

Muchas mujeres, procedentes de todos os estratos de la sociedad, tomaron parte en la lucha del pueblo sajón en Dresden desde 3 al 9 de mayo. Muchas ayudaron a construir barricadas, transportando piedras y muebles, otras suministraban en las calles a los combatientes las comidas que habían preparado. Además, otras cuidaban de los heridos, vendaban sus heridas bajo la lluvia de balas en la misma calle o los arrastraban hacia su propia casa. Una doncella, cuyo prometido había caído el primer día, defendió una barricada durante tres días con el coraje de un león, disparando y matando muchos soldados hasta que ella misma fue derribada por una bala enemiga. $^{22}$

En París, las mujeres se organizaban en Clubes Políticos o Asociaciones de Trabajadoras. Surge la Unión de Parteras, el Club Fraternal de las Lavanderas, la Asociación de las Serviciales que, unidas a otros grupos de mujeres, en 1848 exigen derecho al voto. Las mujeres desempeñaron asimismo activo papel en el levante Comuna de París de 1871. Los primeros días, miles de mujeres con sus hijos en los brazos cercaron las tropas gubernamentales, diciendo a los soldados que no disparasen, porque en la multitud también estaba su mujer con su hijo, o su madre. Esa acción femenina hizo que los soldados bajaran las armas, seguidos por sus propios comandantes. ${ }^{23}$

Como se ve, las mujeres han sido especialmente activas en las etapas iniciales de las revoluciones y aprovecharon la oportunidad para crear nuevas organizaciones e instituciones de su interés. Sin embargo, terminado el periodo de grandes contiendas políticas, alrededor del fin del siglo XIX, pocas mujeres de la clase trabajadora, casadas o solteras, se podían permitir no trabajar. Lo cierto es que la mujer de los estratos sociales directamente vinculados a la producción de bienes y servicios nunca fue ajena al trabajo. Sobre el tema, recuerda Saffioti que en todas las épocas y en todos los lugares la mujer siempre ha contribuido a la subsistencia de su familia y para crear la riqueza social. En las economías precapitalistas, en la etapa inmediatamente anterior a la revolución agrícola e industrial, la mujer de las clases trabajadoras era activa, trabajaba en los campos, en las manufacturas, en las minas, tiendas, mercados y talleres; tejía e hilaba, fermentaba la cerveza y realizaba las tareas domésticas. ${ }^{24}$ Su sueldo era esencial tanto para su propia subsistencia, como para la de su familia. Si bien las mujeres ya habían demostrado su valor y su aptitud para cualquier trabajo, sólo les estaba permitido trabajar en actividades relacionadas con el hogar: lavandería, limpieza, manufactura textil, servicios domésticos, cuidado de los niños - sectores despreciados de la economía - y sus sueldos, tradicionalmente, eran entre la mitad y dos tercios de lo que se pagaría a

\footnotetext{
${ }^{21}$ ANDERSON, Bonnie S.; ZINSSER, Judith. Historia de las Mujeres. Una historia propia. Barcelona: Critica, 2009. p. 771.

22 OTTO, Louise. "Dem Reich der FreiheitWerb'ichBürgerinner". Citação tomada de ANDERSON, Bonnie S.; ZINSSER, Judith. Historia de lasMujeres. Una historia propia. Barcelona: Critica, 2009. p. 771.

${ }^{23}$ ANDERSON, Bonnie S.; ZINSSER, Judith. Historia de las Mujeres. Una historia propia. Op. cit., p. 771.

${ }^{24}$ SAFFIOTI. Heleieth I. B. A mulher na sociedade de classes. 3ạ ed. São Paulo: Expressão Popular. 2013. pp. $61 / 62$.
} 
un hombre por el mismo trabajo. En 1903, el Comité de Mujeres del Consejo de Sindicatos de Manchester y Salford publicó un informe en el que relataba:

Um homem se considera mal pago se ganhar menos de 17 chelins por semana. Não é nenhum exagero dizer que há milhares de mulheres em Manchester que se consideram afortunadas se levam para casa 7 chelins no fim de semana e mulheres de mais idade e maior qualificação profissional que não podem esperar nunca ganhar mais de 12 chelins por semana. ${ }^{25}$

También hay que subrayar la marginación de las mujeres en el propio lugar de trabajo, siempre preteridas con relación a los hombres y sin voz en todo proceso de decisión, a lo que hay que añadir la doble jornada de trabajo a la que quedaban sometidas, por las tareas en su propio hogar. Unido a que cada vez resultaban más evidentes esas injusticias, a mediados del siglo XIX el feminismo se va estructurando en movimiento. El ideario feminista se amplía y las aspiraciones ya no son únicamente la consecución de derechos políticos (votar y ser votado), sino de derechos jurídicos (control sobre la propiedad y la persona), derecho a la educación, acceso al ejercicio profesional y a las jerarquías institucionales. ${ }^{26}$

Esa ha sido una lucha tenaz, pues, como recuerda Kymlicka,

até quase metade do séc. XIX, a maioria dos teóricos políticos defendia haver um fundamento natural para que as ações femininas ficassem restritas à família e à sujeição ao marido. As restrições aos direitos civis e políticos das mulheres eram justificadas pela inaptidão natural das mulheres para com as atividades políticas e econômicas fora do lar. Essa ideia foi progressivamente abandonada pelos teóricos contemporâneos que defendiam a necessidade de que todos os indivíduos, independente do sexo, fossem vistos como livres e iguais, autodeterminadas e dotadas de senso de justiça. ${ }^{27}$

A las puertas del siglo $\mathrm{XX}$, la vida en las ciudades europeas comienza a mejorar sensiblemente. La comprensión de que las enfermedades infecciosas provenían principalmente de las precarias condiciones de higiene, conllevó al abastecimiento público de agua no contaminada a todos los distritos y barrios de las ciudades. Las aguas ya utilizadas, inclusive las fecales, eran drenadas a zonas lejanas, evitando contaminación. Las calles empezaron a estar limpias, los caminos pavimentados, llega el abastecimiento público de gas y electricidad, las casas y la alimentación experimentan una considerable mejoría derivada de la salud pública. Los requisitos para la construcción exigían una mejor ventilación, prevención del calor y del frío, así como un tamaño mínimo. La leche, ahora pasteurizada, embotellada, proporcionó a las mujeres que trabajaban fuera del hogar un medio seguro para alimentar a sus hijos pequeños. La mayoría de los países estableció que los niños pasaran de ocho a diez horas en la escuela - lo que hace desaparecer el trabajo infantil

\footnotetext{
25 Ídem. p. 771

26 BIOSCA, Elena Grau. Feminismo. In: MELLÓN, Joan, Antón. Ideologías y Movimientos Políticos Contemporáneos. 2. ed. Madrid: Tecnos, 2008. p. 413.

${ }^{27}$ KYMLICKA, Will. Filosofia política contemporânea: uma introdução. São Paulo Martin Fontes, 2006. pp. 304305.
} 
- y el analfabetismo prácticamente desaparece en Europa - excepto en los países periféricos. En resumen, en los primeros años del siglo $X X$, las mujeres comienzan a vivir mucho mejor que sus antecesoras. Será precisamente a lo largo del siglo XX cuando las mujeres lleven a cabo una revolución simbólica que acabó con su reconocimiento como sujeto de derechos, abriéndoles las puertas para posibilidades ni siquiera imaginadas, incluso en el pasado reciente.

Después de la II Guerra Mundial, el reconocimiento formal generalizado de la igualdad entre sexos - al menos en los Estados democráticos occidentales - les garantizó derechos de ciudadanía a todos. Como dice Garretas, la lucha feminista alcanzó sus objetivos en el mundo occidental moderno en el instante en que los Estados expresaron en su principal documento jurídico - la constitución - que mujeres y hombres son iguales. El principio de la igualdad se transformó, por tanto, en una cuestión de Estado. ${ }^{28}$

Sin embargo, como todo movimiento social, el feminismo o la lucha por la igualdad de derechos ha sufrido críticas y reacciones contrarias. Resumidamente, citamos las cuatro principales:

a) Odio - Las feministas están promoviendo el odio contra los hombres, o intentando mostrar la superioridad femenina. Argumentan algunos críticos que si en los manifiestos feministas las palabras "hombre" y "mujer" fueran sustituidas por "negro" y "blanco", respectivamente, se transformarían, naturalmente, en manifiestos racistas.

b) Suicidios - Esta crítica, que proviene principalmente de los Estados Unidos, afirma que la tasa de suicidio entre hombres ha aumentado considerablemente en las últimas décadas, superando significativamente la tasa entre mujeres. Concluyen que ello sucede porque los hombres se consideran oprimidos debido a la contra opresión por parte de las mujeres.

c) Destrucción - Una tercera crítica surge desde grupos conservadores que consideran el feminismo como destructor de las funciones tradicionales de los géneros y de los valores de la familia, especialmente cuando en la pareja la mujer es trabajadora con éxito por lo que 'abandona' la educación de los hijos y la dedicación a la familia.

d) Injusticia - Otro reproche es que, por presión de los movimientos feministas, el Poder Judicial pierde su imparcialidad convirtiéndose en tendencioso, privilegiando a las mujeres en disputas legales, aparentemente de género (custodia de los hijos, causas de divorcio, acoso sexual), invirtiendo el orden del cargo y muchas veces creando situaciones en las que sería casi imposible para un acusado probar su inocencia.

Otras críticas se dirigen contra los gobiernos, a los que se acusa de recurrir a acciones afirmativas en beneficio de las mujeres y con ello, al favorecerlas, violar el principio de la igualdad. ${ }^{29}$

Independientemente de las críticas, el hecho es que el movimiento ha logrado importantes avances en la cuestión de la igualdad entre los sexos, siendo responsable de cambios sustanciales en las sociedades occidentales. Mediante reivindicaciones articuladas ha sido como las mujeres conquistaron el derecho a la participación política plena, mayores oportunidades de trabajo con paridad de sueldos a los de los hombres, oportunidades y promociones equiparadas, derecho al

28 GARRETAS, Maria M. Rivera. El fraude de la igualdad. Los desafíos del feminismo hoy. Barcelona: Planeta, 1997. Citação tomada de: BIOSCA. Elena Grau. Feminismo. In: MELLóN, Joan, Antón. Ideologías y Movimientos Políticos Contemporáneos. 2. ed. Madrid: Tecnos, 2008. p. 414.

${ }^{29}$ Ver: <htpp//pt.wikipedia.org> 
divorcio y el control sobre su propio cuerpo en cuestiones relacionadas con la salud. En las últimas décadas, se ha acelerado el proceso de evolución de la igualdad. Desde una situación de dependencia de la mujer en relación al varón, se ha evolucionado a una situación de independencia. La mujer sale del mundo privado para incorporarse al mundo del trabajo, alcanzando la igualdad formal en el ámbito jurídico, controla su maternidad y se acerca, cada vez más, al rol de actividades tradicionalmente desempeñadas por el hombre. Efectivamente, la mujer está más presente en el ámbito público y el hombre también empieza a estar presente en el ámbito doméstico. Funciones tradicionalmente opuestas ahora son compartidas, asumidas por uno u otro sexo, dependiendo básicamente de la educación y del aprendizaje.

A lo largo del tiempo, el movimiento feminista, el movimiento de defensa de los derechos de las mujeres, se dividió en innúmeras corrientes e ideologías. Evidentemente, todas ellas consideran y reivindican que hombres y mujeres son iguales y deben, por tanto, tener los mismos derechos y las mismas oportunidades. No hay unanimidad en cuanto al número de ideologías variadas, pero algunos investigadores dividen el movimiento feminista de acuerdo al periodo histórico, otros por ideología, por el objeto principal de la reivindicación, por la fundamentación teórica, etc. Así se encuentran referencias de cinco a diez corrientes feministas. De nuestra parte, optamos por referirnos a cuatro, que consideramos las principales:

Feminismo socialista - El pensamiento socialista, en sus análisis de la sociedad y proyecciones de futuro, siempre tomó en consideración la situación de las mujeres. Pero, como bien advierte Miguel: Esto no significa que el socialismo sea necesariamente feminista, sino que en el siglo XIX comenzaba a resultar difícil abanderar proyectos igualitarios radicales sin tener en cuenta la mitad de la humanidad. ${ }^{30}$ Los socialistas utópicos fueron los primeros a incluir en su discurso este tema. Aseveran que la opresión de las mujeres no proviene del hombre, sino del sistema. Si los análisis feministas liberales carecían de una interpretación materialista de la historia, la doctrina marxista es insuficiente para explicar la opresión de la mujer. Denuncian que el trabajo de la mujer es doblemente aprovechado por las sociedades patriarcales: por los hombres y por el sistema. La lucha del movimiento, por tanto, no es contra el hombre, sino contra el sistema. Para Miguel, esta defensa de las mujeres puede ser justificada por la gran importancia que atribuye el socialismo utópico a la transformación de la institución familiar. Condenaban la doble moral y consideraban el celibato y el matrimonio indisoluble como instituciones represoras y causas de la injusticia y de la infelicidad.

Feminismo liberal - En 1966 surge en los EEUU una de las mayores y más poderosas organizaciones feministas: la Organización Nacional de las Mujeres (NOW). Este movimiento de orientación liberal/burguesa, compuesto básicamente de mujeres de la clase media, se caracteriza por definir la situación discriminatoria de la mujer como una cuestión de desigualdad y no de opresión o explotación. Identificaron como problema principal de las mujeres su exclusión de la esfera pública, por tanto, desde comienzos del movimiento poseen una sección destinada a formar y promover a las mujeres para ocupar cargos políticos. En resumen, las liberales demandan básicamente una reforma

\footnotetext{
${ }^{30}$ MIGUEL, Ana de. “Feminismos”. In AMARÓS, Celia. 10 Palabras Claves sobre Mujer.4a ed. Estella: evd. 2007. p. 230.
}

Revista do Direito [ISSN 1982-9957]. Santa Cruz do Sul, v. 1, n. 54, p. 40-58, jan./abr. 2018. https://online.unisc.br/seer/index.php/direito/index 
en el sistema hasta alcanzar la igualdad formal entre los sexos, principalmente en lo que se refiere a los derechos políticos, educacionales y laborales.

Feminismo radical - El feminismo radical surge y se desarrolla en los EEUU entre los años 1967 y 1975. Su base teórica puede ser encontrada en las obras Política Sexual de Kate Millet y La dialéctica de la Sexualidad de Sulamith Firestone, ambas publicadas en 1970. Uniendo teorías marxistas, de psicoanálisis y anticolonialismo, estas obras acuñaron conceptos básicos y fundamentales para el análisis femenino de cómo el patriarcado asumió la dominación sexual. Esta corriente defiende que la dominación patriarcal no es un subproducto del capitalismo. Incluso cuando desaparezca tal capitalismo, las mujeres seguirán subordinadas en sociedades y familias, donde los hombres ostentan el poder, porque la opresión de las mujeres proviene de la supremacía masculina. Está centrado en la cuestión de la sexualidad y radica - como forma de toma de poder para contraponerse al poder masculino - que las mujeres deben ser capaces de controlar la propia fecundidad, a través de métodos contraceptivos, interrupción del embarazo, etc. Una de las razones de su declive fue la radicalidad igualitarista y anti-jerárquica: ninguna mujer estaba por encima de otra. Las líderes estaban mal vistas y una de las constantes preocupaciones del grupo fue la de crear reglas para evitar que ejerciesen el predominio las más bien dotadas o preparadas. Miguel explica que era frecuente que se escuchase de las líderes, antes de cualquier manifestación, la siguiente frase: "pido perdón a nuestras hermanas por hablar en nombre de ellas". ${ }^{31}$

Feminismo de diferencia - Mientras los movimientos feministas de varias corrientes, y también el feminismo socialista, liberal y radical luchan por la superación de los géneros, surge una corriente que parece querer afirmarse en la diferencia. En Europa, pero especialmente en Francia e Italia, surge un feminismo que se autoproclama defensor de la diferencia sexual. Parte desde la distinción entre las dos culturas: la masculina - cuyo eje central está en la agresividad, competitividad, autoridad, individualismo y racionalidad - y la femenina - en la cual se destacan la empatía, colaboración y los sentimientos. Defiende la liberación de las mujeres a través del desarrollo de una nueva cultura femenina. Aboga porque las mujeres desarrollen una cultura diferente, una cultura que destaque los valores femeninos como superiores a los masculinos. En lugar de desvalorizar la naturaleza femenina, especialmente en lo que se refiere a la maternidad, la misma debe ser valorada por encima de la cultura masculina. ${ }^{32}$

De una manera general, en los países occidentales, son muchas las políticas públicas de igualdad de género o incluso acciones afirmativas en favor de la mujer: sensibilización y educación, medidas en el ámbito de la salud, medidas de fomento al empleo, medidas institucionales, medidas de seguridad, procesales y jurídicas - en el ámbito de la violencia contra la mujer - derechos económicos como ayudas sociales, derecho de acceso a vivienda, creación de observatorios estatales y autónomos, y tantas otras. Junto a estas medidas de carácter legal, hay que subrayar las significativas aportaciones que la jurisprudencia ordinaria $y$, especialmente, la de las Cortes y Tribunales Constitucionales, ha desarrollado en orden a clarificar normativa, proclamar la inconstitucionalidad de leyes que imponían una discriminación, a clarificar e interpretar.

\footnotetext{
${ }^{31}$ Para profundizar ver: MIGUEL, Ana de. "Feminismos". In AMARÓS, Celia. 10 Palabras Claves sobre Mujer.4a ed. Estella: evd. 2007. p. 217 y ss.

${ }^{32}$ Ver: SOTARO, Michael J. Política y Ciencia Política. Madrid: McGRAW-HILL, 2006. pp. 244-245.
} 


\section{LA PROTECCIÓN INTERNACIONAL}

A partir de los movimientos feministas comienza, en los años setenta, el ciclo de Conferencias de la ONU, conocido como la "Década de la Mujer".

En 1975, bajo los auspicios de la ONU, con la participación de 133 Estados y 6.000 representantes de ONG's, se celebra en México la I Conferencia Internacional sobre la Mujer. En esta Conferencia se definió un plan de acción mundial para la consecución de los objetivos del Año Internacional de la Mujer que incluía un amplio conjunto de directrices para el reconocimiento y la emancipación plena de las mujeres hasta 1985.

En 1979, la Asamblea General de las Naciones Unidas aprobó la Convención sobre la Eliminación de todas las Formas de Discriminación contra la Mujer. Esta Declaración Internacional entró en vigor el 03 de septiembre de 1981, siendo ratificada por 188 Estados (Estados Unidos de América y Palau firmaron, pero no ratificaron, mientras Santa Sé, Irán, Somalia, Sudán y Tonga rechazaron adherirse al Tratado).

En 1980 se celebró la Conferencia de Copenhague. Con la participación de 145 Estados, tenía como objetivo discutir los avances que se habían producido desde la primera Conferencia Mundial, especialmente en las cuestiones relacionadas con trabajo, salud y educación. En esta Conferencia se aprobó un plan de acción para exigir que los Estados aporten políticas públicas más firmes para garantizar la adquisición y el control de la propiedad de parte de las mujeres, y asimismo la adopción de medidas para la protección de los derechos de herencia, custodia de los hijos y garantía de la nacionalidad de la mujer.

Las Naciones Unidas han organizado cuatro conferencias mundiales sobre la mujer, que se celebraron en Ciudad de México (1975), Copenhague (1980), Nairobi (1985) ${ }^{33}$ y Beijing (1995). A ésta última siguió una serie de exámenes quinquenales.

Un importante avance se consiguió en 1993, durante la II Conferencia de Derechos Humanos de la Organización de las Naciones Unidas (conferencia de Viena) donde se produjo el reconocimiento expreso de la discriminación y la violencia contra la mujer, pasando a considerarse un problema de la sociedad y no más una cuestión privada.

En el ámbito de las Américas, merece mención la Convención de Belém do Pará Convención Interamericana para Prevenir, Punir y Erradicar la Violencia contra la Mujer (junio de 1994)..$^{34}$

La Cuarta Conferencia Mundial sobre la Mujer, celebrada en Beijing en 1995, marcó un importante punto de inflexión para la agenda mundial de igualdad de género. Con la participación de

\footnotetext{
${ }^{33}$ En julio de 1985, la ONU reunió en Nairobi, Kenia, a más de 1.900 delegados de 157 Estados y un foro paralelo de aproximadamente 12.000 participantes de ONG's para la Conferencia Mundial para el Examen y Evaluación de los Avances en el Decenio de las Naciones Unidas para la Mujer. En esta conferencia se aprobaron vastas directrices para el establecimiento de medidas concretas para superación de los obstáculos que impedían la consecución de los objetivos del Decenio. Los Estados se comprometieron a adoptar medidas nacionales para la promoción de la igualdad de género y promover la participación de las mujeres en la vida pública.

${ }^{34}$ Disponible en: <https://www.oas.org/dil/esp/convencion_belem_do_para.pdf>
} 
más de 6.000 delegados gubernamentales y más de 4.000 representantes de ONG's, tuvo como tema central "Acción para la Igualdad, el Desarrollo y la Paz". Esta Conferencia partió de los acuerdos políticos y de los avances ya conseguidos en razón de las tres Conferencias anteriormente realizadas y consolidó cinco decenios de avances jurídicos destinados a garantizar la igualdad entre hombres y mujeres. La Declaración y Plataforma de Acción de Beijing, adoptada de forma unánime por 189 países, constituye un programa en favor del empoderamiento de la mujer y en su elaboración se tuvo en cuenta el documento clave de política mundial sobre igualdad de género. ${ }^{35}$

El 02 de julio de 2010, la Asamblea General de las Naciones Unidas aprobó, por unanimidad, la creación de un órgano encargado de acelerar las Políticas para que se alcance la igualdad de género y el fortalecimiento de la plena autonomía de las mujeres. En septiembre, el SecretarioGeneral de la ONU, Ban Ki-moon, nombró como Subsecretaria-General del nuevo órgano de la ONU para la Igualdad de Género y el Empoderamiento de las Mujeres, la ONU-MUJER, a la ex-presidente de Chile, Michelle Bachelet. ${ }^{36}$

\section{LA LUCHA POR LA IGUALDAD DE GÉNERO EN BRASIL}

En Brasil, el movimiento feminista puede ser dividido en dos momentos. El primero va desde el fin del siglo XIX al año de 1932, cuando las mujeres, con casi un siglo de retraso en relación a los hombres, adquieren derechos políticos. Es denominado como "bien comportado", puesto que no cuestionaba la opresión de la mujer, y buscaba únicamente su inclusión en la ciudadanía, no existiendo el deseo de alterar las relaciones de género. A comienzos del siglo XX, cuando el incipiente proletariado brasileño luchaba por derechos laborales, era significativa la participación de mujeres en las huelgas y en comicios. ${ }^{37}$

Sin embargo, en la conquista de los derechos políticos por las mujeres hubo poco tiempo para celebración, porque con el golpe de Estado y el comienzo del Estado Nuevo, resultó inviable cualquier manifestación de carácter político y/o reivindicatorio, quedando el propio Poder Legislativo cerrado durante casi una década. Con la promulgación de la Constitución, el 10 de noviembre de 1937, el retroceso y la usurpación de derechos alcanzan a todos pero, en lo que se refiere a la mujer, la Constitución silencia el derecho al voto. Por su parte, el gobierno promulga el Decreto n 3.199/37, por el cual se prohíbe a las mujeres la práctica de deportes "incompatibles con la condición femenina", como luchas de cualquier naturaleza, fútbol (de salón y de playa), polo, polo acuático, levantamiento de pesas y beisbol. Con la redemocratización del país, la Constitución promulgada el 18 de septiembre de 1946 restituyó expresamente los derechos políticos a las mujeres. En ese período tiene inicio, aunque de forma tímida, una movilización de las mujeres que participan en algunas campañas, pero que no llegan a poder considerarse un movimiento feminista.

\footnotetext{
${ }^{35}$ La Declaración y Plataforma de Acción de Beijing establece una serie de objetivos estratégicos y medidas para el progreso de las mujeres y el logro de la igualdad de género en 12 esferas clave, que se pueden consultar en: <http://www.unwomen.org/es/how-we-work/intergovernmental-support/world-conferences-on-women> ${ }^{36}$ Vid. Las Naciones Unidas y la mujer: < http://www.un.org/es/sections/issues-depth/women/index.html>.

${ }^{37}$ Para profundizar ver SAFFIOTI. Heleieth I. B. A mulher na sociedade de classes. 3a ed. São Paulo: Expressão Popular. 2013. p. 349 y ss.
} 
A partir de 1964 inicia un nuevo período totalitario y, una vez más, no resulta viable ninguna posibilidad de manifestación política y/o reivindicatoria. En la Constitución promulgada el 24 de enero de 1967, junto con la Enmienda Constitucional $n^{\circ}$ 1, del 17de octubre de 1969 que la modifica completamente, no se vislumbra ningún atisbo de regulación que beneficie a la condición femenina. En este periodo de represión, las mujeres brasileñas, siguiendo el ejemplo del movimiento feminista que eclosionaba en Europa y en los Estados Unidos, se organizaron en acciones contra el régimen de excepción. Inicialmente liderado por mujeres con maridos y familiares perseguidos por el gobierno totalitario, el movimiento feminista recibió la atención de la sociedad y encontró apoyo en organizaciones sociales y en grupos políticos. ${ }^{38}$

Tiene inicio entonces, en este periodo, un segundo momento del movimiento feminista en Brasil que se extiende hasta la actualidad. Reúne militantes de varias corrientes y pensamientos políticos - anarquistas, intelectuales, líderes operarias - y, además de la participación política, defienden el derecho a la educación, discuten la dominación masculina y abordan temas delicados, como la cuestión de la sexualidad, del divorcio y, más recientemente, el aborto. Por estas razones, es denominado como "mal comportado".

Como reflejo del Plan de Acción elaborado por la ONU, en la I Conferencia Mundial sobre la Mujer (México - 1975), en 1977 se instaura una Comisión Parlamentaria de Averiguación para verificar hasta qué punto la legislación brasileña vigente en aquel momento contribuía para mantener la posición de inferioridad de la mujer y qué puntos deberían ser alterados. La Comisión investigó la situación de la mujer en el mercado laboral, en la familia y en la sociedad. Fueron señaladas cuestiones no político-partidarias, sino de absoluta relevancia y que permanecen hasta hoy como marcas de la desigualdad todavía endosadas a las mujeres en Brasil. ${ }^{39}$

A partir de los años 1980, las mujeres retoman con vitalidad su participación en la sociedad. Se organizaron en grupos para reflexión, publicación de periódicos, discusiones sobre sexualidad, derechos, salud, violencia de género, y otros temas. Uno de los frentes de lucha fueron las denuncias sobre la desvaloración de la mujer y, en especial, la violencia de género. En todo el país se organizaron comités para denuncias de violencia y apoyo a las mujeres víctimas. En varios Estados se consiguió crear Casas de la Mujer, SOS-Violencia, etc. La Constitución de 1988 dio nuevo carácter a las estructuras de poder en el país. Delineó con claridad los derechos fundamentales, las garantías individuales y las libertades civiles, garantizando a las mujeres, de forma expresa, el derecho a la igualdad y a la titularidad de la plena ciudadanía, facilitando mayor inserción femenina en los espacios sociales y en la vida política de la Nación.

En las primeras elecciones que siguieron a la proclamación de la Constitución, en 1990 es elegida la primera mujer para el cargo de senadora ${ }^{40}$ y el Presidente de la época designa una primera

\footnotetext{
${ }^{38}$ Sobre la relación entre mujer y política durante el régimen militar ver COLLING, Ana Maria. A resistência da mulher à ditadura militar no Brasil. Rio de Janeiro: Rosa dos Tempos, 1997.

${ }^{39}$ Fueron oídas 39 personalidades de los más diversificados sectores para examinar la situación de la mujer en todos los ramos de actividades. Para ello, fueron promovidos estudios y audiencias públicas, de marzo a octubre de 1977. Ver SANTOS, Tânia Maria dos. A mulher nas constituições brasileiras. Disponible en: <www6.ufrgs.br/nucleomulher/.../Mulher\%20 e\%20CF\%20-\%20Final\%20tania.pdf>. p. 10.

${ }^{40}$ Júlia Marise. PMDB/MG
} 
ministra del sexo femenino ${ }^{41}$. En las elecciones siguientes, en 1994, es elegida la primera gobernadora de un Estado Brasileño (reelecta en 1998). ${ }^{42}$ Desde 2003, Brasil cuenta con una Secretaría de Políticas para las Mujeres, vinculada directamente a la Presidencia de la República para asesorar al Jefe de Gobierno en la promoción de la igualdad de género a través de la formulación, coordinación y articulación de políticas públicas para las mujeres, además de elaborar e implementar campañas educativas y no discriminatorias, así como acompañar la implementación de legislación y políticas públicas antidiscriminatorias.

En 2010, Brasil se eligió a una mujer para su más alto cargo político, la de Presidenta de la República. Se evidencia con esa importante conquista histórica para las mujeres que, desde la elección de la primera mujer para un cargo político, en 1929, la participación femenina en la vida pública creció y se fortaleció. ${ }^{43}$

\section{UNA VISIÓN DE LA REALIDAD}

Llegamos al tercer milenio con el pleno reconocimiento legal de la igualdad entre los sexos. Sin embargo, respecto de la ascensión política y social de las mujeres, de las innumerables políticas públicas de acciones afirmativas, con el reconocimiento formal de idénticas responsabilidades y derechos en la formación y en el acceso a la participación en los espacios sociales, la capacidad de las mujeres todavía no está plenamente aprovechada y resulta poco expresiva en los foros de poder y decisión de la vida nacional.

Como consta en informe final de la Comisión Tripartita para revisión de la Ley n 9.504/77, elaborado por la Secretaría de Política para, de manera meramente formal, cumplir las exigencias de la legislación electoral, la candidatura y el ejercicio de cargos públicos por parte de las mujeres ya resulta habitual en las organizaciones de partidos, sindicales y sociales de Brasil. Sin embargo, todavía estamos muy lejos de la representación femenina justa. Si bien son poco más del $50 \%$ de la población, las mujeres apenas alcanzan el porcentaje de un $10 \%$ en el Congreso Nacional, muy por debajo del promedio mundial del $18,5 \%$ de mujeres en el Parlamento". ${ }^{44}$

Además, la Síntesis de Indicadores Sociales (2016) del Instituto Brasileño de Geografía y Estadística - IBGE demuestra que aumentó considerablemente el porcentaje de mujeres responsables del hogar. En las familias con hijos, el porcentaje pasó del 6,8\% al 22,5\%. En las parejas sin hijos, el porcentaje pasó del 8,4\% al 22,0\%. En el cómputo general, en el periodo de 2004 a 2014 , el número de hogares en las que una mujer está al frente creció el $67 \%{ }^{45}$

\footnotetext{
${ }^{41}$ Zélia Cardoso de Mello. Ministra de la Economía.

${ }^{42}$ Roseana Sarney, gobernadora del Estado de Maranhão.

${ }^{43}$ Alzira Soriano fue elegida en 1928 alcaldesa del municipio de Lajes (Rio Grande do Norte) con $60 \%$ de los votos, volviéndose la primera alcaldesa elegida en América Latina.

${ }^{44}$ BRASIL. Presidência da República. Secretaria de Políticas para as Mulheres. Comissão Tripartite para revisão da Lei 9.504/1977: Relatório Final. Brasília: Secretaria de Políticas para as Mulheres, 2010. p. 7.

${ }^{45} \mathrm{http}: / /$ www.ibge.gov.br/home/estatistica/pesquisas/pesquisa_resultados.php?id_pesquisa=47
} 
Por otro lado, en el mercado laboral, si bien las mujeres han conquistado puestos de mando y decisión, su remuneración continúa siendo muy inferior a la masculina. Además de rendimientos inferiores, las mujeres continúan preteridas por el mercado, pues constituyen el grupo con mayor tasa de desempleo, por debajo solamente de los jóvenes sin experiencia.

Una investigación realizada por el Grupo Catho ${ }^{46}$ deja muy claro que las mujeres perciben un salario inferior al de los hombres en todos los cargos, llegando a la diferencia astronómica del $120 \%$ para una misma función. El estudio demuestra que para cargos operacionales, la diferencia salarial llega al 58\%, para un especialista licenciado es del 51,4\%, técnicos el 47,3\%, coordinación, gerencia y directorio el $46,7 \%$, supervisor y encargado el $28,1 \%$, analistas el $20,4 \%$, auxiliares y asistentes el 9\%. En el análisis de 25 sectores de la economía, los hombres son mejor remunerados en 22 de esos sectores. La mayor diferencia está en el sector de la educación (cursos de idiomas, cursos de preparación para pruebas de selección de universidades), llegando al 116,4\%. En el sector de seguros la diferencia salarial es, como promedio, del 97,7\%. Las mujeres reciben más que los hombres únicamente en el sector de comunicación social, producción de eventos y gimnasios de deportes, donde el promedio de la diferencia va del 20 al $30 \% .{ }^{47}$

No se puede olvidar la cuestión de la doble jornada. Aunque haya crecido la participación masculina en las funciones domésticas, las mujeres todavía dedican, de promedio, 21 horas semanales para cocinar, limpiar la casa, cuidar a los hijos, lavar la ropa, etc., mientras los hombres dedican, como máximo, 10 horas. ${ }^{48}$

Pero los peores indicadores están en el campo de la violencia. Brasil es signatario de todas las Convenciones Internacionales y adopta Políticas Públicas de protección a la mujer (como la creación de la Secretaría Nacional de Políticas para las Mujeres, la promulgación de la Ley no 11.340/2006 - Ley Maria da Penha, ${ }^{49}$ la creación de Casas Refugio, la creación del Plan Nacional de Políticas para las Mujeres (2004), la promulgación de la Ley ํㅜ 13.104/2015 - tipificando el crimen de feminicidio), pero todavía ocupa la 5a posición mundial en muerte de mujeres. Cada dos horas una mujer es asesinada y cada 11 minutos una mujer es víctima de violencia. La tasa de feminicidio es del 4,8 para 100 mil mujeres, según datos de la Organización Mundial de la Salud. En 2015, el Mapa de la Violencia mostró que la muerte de mujeres negras, de 2003 a 2013, creció el 54\%, pasando de 1.864 para 2.875. En el mismo periodo, la muerte de mujeres blancas cayó el 9,8\%, subiendo de 1.747 en 2003 para 1.576 en 2013. Del total de feminicidios registrados en 2013 , el $33,2 \%$ de los homicidas eran compañeros o ex-compañeros de las víctimas.

\footnotetext{
${ }^{46}$ Catho.com.br/empresas/pesquisa-salarial. Acceso el 13.03.2017.

${ }^{47}$ Ver también G1.globo.com/economia. Acceso el 13.03.2017.

${ }^{48}$ www1.folha.uol.com.br/mercado. Acceso el 17.03.2017.

49 < https://oig.cepal.org/sites/default/files/ley_11.340_maria_da_penha_de_brasil.pd>.
} 


\section{CONSIDERACIONES FINALES}

Como se ha expuesto, la lucha por la igualdad de derechos entre los géneros es tan antigua como la desigualdad. Al principio, producto de la rebeldía individual de algunas mujeres, obstinación por el reconocimiento de su existencia y de sus derechos en cuanto ser humano. Más tarde, bajo la égide del movimiento iluminista, una demanda colectiva, articulada, reivindicaciones de enfrentamiento a la injusticia. Parece cierto que el movimiento feminista como lo conocemos, articulado con exigencias de universalidad, de igualdad, justicia y emancipación es producto de la fundamentación/reivindicación iluminista.

Como la historia nos ha demostrado, el iluminismo no supo cumplir sus promesas y reivindicaciones y, particularmente, el feminismo permaneció fuera del foco de las luces que dieron paso al 'nuevo' mundo. Así, la mujer no fue plenamente incluida en el contrato social, en el ámbito público, en la ciudadanía. Y, después de las grandes manifestaciones de fuerza y vitalidad, después de algunos avances y conquistas, especialmente a partir de los años sesenta hasta finales del siglo $\mathrm{XX}$, todo indica que, al menos, las primeras décadas del siglo XXI han entrado a formar parte de la historia como un periodo absolutamente conservador. El movimiento feminista posee todavía innumerables desafíos para concretizar una efectiva igualdad. Los principales obstáculos se refieren a la violencia y al trabajo. Ambos necesitan políticas públicas contundentes, además de una firme y comprometida implicación de instituciones públicas y privadas.

Sin embargo, después de la victoria de líderes conservadores y nacionalistas en los EEUU, en Francia, España, Inglaterra, en la propia Rusia, así como en muchos países periféricos, después del retorno del modelo de Estado liberal con el fin de la utopía de una izquierda ética en América Latina, evidentemente, los movimientos sociales no desaparecerán, pero tendrán que adaptarse al nuevo modelo de Estado y la conquista de derechos se hará más penosa.

Por tanto, la igualdad de derechos de género continúa siendo una lucha inacabada.

\section{REFERÊNCIAS}

ALAMBERT, Zuleika. Feminismo. O ponto de vista marxista. São Paulo: Nobel, 1986. p. 4-6; Las feministas de la Edad Media. In: XL Semanal n 1218 (27.02.2011).

ANDERSON, Bonnie S.; ZINSSER, Judith. Historia de las Mujeres. Una historia propia. Barcelona: Critica, 2009.

BELLOSO MARTíN, N., "Algunas propuestas para la prevención y la lucha contra la violencia de género: reflexiones sobre la oportunidad de la tipificación del feminicidio" en Clovis Gorzevski (Organizador), Direitos Humanos e Participacâo Política. Vol. VI, Porto Alegre: Imprensa Livre, 2015. BELTRÁN PEREIRA, E., "Público y Privado (Sobre feministas y liberales: argumentos en un debate acerca de los límites de lo político)" en DOXA, n¹5-16, 1994. Disponible en: $<w w w . c e r v a n t e s v i r t u a l . c o m / . . . / p b l i c o-y-p r i v a d o--s o b r e-f e m i n i s t a s-y-l i b e r a l e s-a r g u m e n t . . .>$.

BIOSCA, Elena Grau. Feminismo. In: MELLÓN, Joan, Antón. Ideologías y Movimientos Políticos Contemporáneos. 2. ed. Madrid: Tecnos, 2008. 
BOURDIEU, P., La domination masculine. Trad. de J. Jordá. La dominación masculina. $2^{2}$ ed., Barcelona: Anagrama, 2000.

BRASIL. Presidência da República. Secretaria de Políticas para as Mulheres. Comissão Tripartite para revisão da Lei 9.504/1977: Relatório Final. Brasília: Secretaria de Políticas para as Mulheres, 2010.

COLLING, Ana Maria. A resistência da mulher à ditadura militar no Brasil. Rio de Janeiro: Rosa dos Tempos, 1997.

DURÁN Y LA LAGUNA, P., "La definición del género" en Los límites del Derecho, Granada: Comares, 1996.

FERNÁNDEZ, E., "Los derechos de las mujeres" en J. Ballesteros (Editor) Derechos humanos. Concepto, fundamento, sujetos, Madrid: Tecnos, 1992.

FRANCISCO DE VITÓRIA. Los Derechos Humanos. Antologia. Salamanca: Editorial San Esteban. 2003.

GARRETAS, Maria M. Rivera. El fraude de la igualdad. Los desafíos del feminismo hoy. Barcelona: Planeta, 1997.

GILLIGAN, C., In a Different Voice. Psychological Theory and Women's Development. Cambrigde: Harvard University Press, 1982;

HEGEL, J.G.F., Filosofía de la Historia universal. Trad. de J. Gaos, Madrid: Revista de Occidente, 1928.

KANT., I., "Respuesta a la pregunta: ¿Qué es la llustración?" en AA.VV., ¿Qué es la llustración?, trad. de A. Maestre y J. Romagosa, Madrid: Tecnos, 1988.

KYMLICKA, Will. Filosofia política contemporânea: uma introdução. São Paulo Martin Fontes, 2006.

MIGUEL, Ana de. "Feminismos". In AMARÓS, Celia. 10 Palabras Claves sobre Mujer.4르 ed. Estella: evd. 2007.

MUMFORD, Lewis. A cidade na história: suas origens, transformações e perspectivas. $4^{\mathrm{a}}$ ed. São Paulo: Martins Fontes. 1998.

OLLERO, A., Discriminación por razón de sexo. Valores, principios y normas en la jurisprudencia constitucional española. Madrid: CEC, 1999;

OTTO, Louise. "Dem Reich der FreiheitWerb'ichBürgerinner". Citação tomada de ANDERSON, Bonnie S.; ZINSSER, Judith. Historia de lasMujeres. Una historia propia. Barcelona: Critica, 2009.

PATEMAN, C. The Sexual Contract, Cambridge:Oxfor,d,, 1988;

PECES-BARBA, G., "De la igualdad normativa a la igualdad de hecho. Las cuotas femeninas en las elecciones" en J.A. López García y J.A. del Real (Editores) Los derechos: entre la ética, el poder y el Derecho, Madrid: Dykinson, 2000.

PECES-BARBA, G., Curso de Derechos fundamentales. Teoría General. Madrid:BOE-Universidad Carlos III, 1995.

PETIT, Cristina Molina. "Ilustración". In: AMORÓS, Celia (org) 10 Palabras clave sobre mujer. 4ª ed. Estella: evd. 1995.

PHILLIPS, A., ¿Las feministas deben abandonar la democracia liberal?, en: "Perspectivas feministas en Teoría política", 
REY MARTÍNEZ, F., El derecho fundamental a no ser discriminado por razón de sexo. Madrid: McGraw-Hill, 1995.

ROUSSEAU, J.J., "L'Emile ou l'education" en Oeuvres complètes de Jean Jacques Rousseau. Vol. IV. Paris: Gallimard, 1969.

ROUSSEAU, Jean-Jacques. Do Contrato Social. São Paulo: Martin Claret. 2002.

RUIZ MIGUEL, A., "Paridad electoral y cuotas femeninas" en Claves de Razón Práctica, 94, 1999.

SAFFIOTI. Heleieth I. B. A mulher na sociedade de classes. 3르 ed. São Paulo: Expressão Popular. 2013.

SOTARO, Michael J. Política y Ciencia Política. Madrid: McGRAW-HILL, 2006.

TOSCANO, Moema; GOLDENBERG, Mirian. A revolução das mulheres: um balanço do feminismo no Brasil. Rio de Janeiro: Revan, 1992.

VALCÁRCEL, Amelia. Feminismo en el mundo global. $4^{a}$ ed. Madrid: Cátedra/Universitat de València. 2012.

WARAT, L.A., "A questão do gênero", en Por quem cantam as sereias. Informe sobre Ecocidadania, Gênero e Direito, Porto Alegre: Síntese, 2000, p.137.

WILSON. Edward O. Da natureza humana. Tradução de Geraldo Florsheim e Eduardo D’Ambrosio. São Paulo: Editora na Universidade de São Paulo. 1981.

YOUNG, I.M., Justice and the Politics of Difference. Trad. de S. Álvarez. La justicia y la política de la diferencia. Madrid: Cátedra-Universitát de Valencia-Instituto de la mujer, 2000.

www.ibge.gov.br/home/estatistica/pesquisas/pesquisa_resultados.php?id_pesquisa $=47$

Catho.com.br/empresas/pesquisa-salarial. Acceso el 13.03.2017.

G1.globo.com/economia. Acceso el 13.03.2017.

www1.folha.uol.com.br/mercado. Acceso el 17.03.2017.

www6.ufrgs.br/nucleomulher/.../Mulher\%20 e\%20CF\%20-\%20Final\%20tania.pdf>.

Las Naciones Unidas y la mujer: <http://www.un.org/es/sections/issues-depth/women/index.html>.

Convención de Belém do Pará - Convención Interamericana para Prevenir, Punir y Erradicar la Violencia contra la Mujer (junio de 1994). Disponible en: $<$ https://www.oas.org/dil/esp/convencion_belem_do_para.pdf>

Cuarta Conferencia Mundial sobre la Mujer, celebrada en Beijing en 1995 <http://www.unwomen.org/es/how-we-work/intergovernmental-support/world-conferences-on-women> Ley Maria da Penha. Ley número 11.340 del 7 de agosto de 2006. Brasil. Disponible en: < https://oig.cepal.org/sites/default/files/ley_11.340_maria_da_penha_de_brasil.pd>.

\section{COMO CITAR ESSE DOCUMENTO:}

MARTíN, Núria Belloso; GORCZEVSKI, Clóvis. Movimiento feminista e igualdad de derechos. Una lucha inacabada.. Revista do Direito, Santa Cruz do Sul, v. 1, n. 54, p. 40-58, june 2018. ISSN 19829957. Disponível em: <https://online.unisc.br/seer/index.php/direito/article/view/11838>. Acesso em: doi:http://dx.doi.org/10.17058/rdunisc.v1i54.11838. 